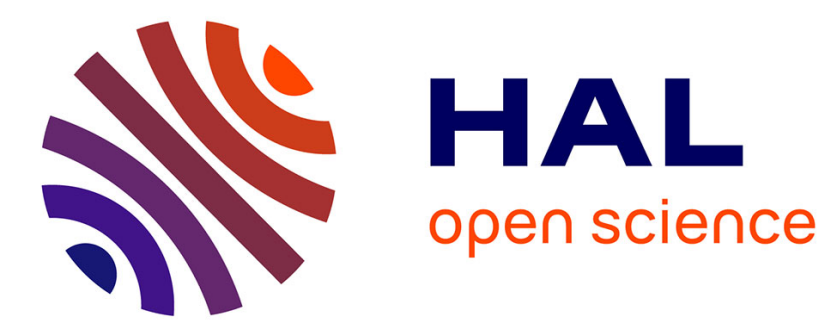

\title{
Tau R3-R4 Domain Dimer of the Wild Type and Phosphorylated Ser356 Sequences. I. In Solution by Atomistic Simulations
}

Philippe Derreumaux, Viet Hoang Man, Junmei Wang, Phuong H. Nguyen

\section{- To cite this version:}

Philippe Derreumaux, Viet Hoang Man, Junmei Wang, Phuong H. Nguyen. Tau R3-R4 Domain Dimer of the Wild Type and Phosphorylated Ser356 Sequences. I. In Solution by Atomistic Simulations. Journal of Physical Chemistry B, 2020, 124 (15), pp.2975-2983. 10.1021/acs.jpcb.0c00574 . hal03087682

\section{HAL Id: hal-03087682 \\ https://hal.science/hal-03087682}

Submitted on 24 Dec 2020

HAL is a multi-disciplinary open access archive for the deposit and dissemination of scientific research documents, whether they are published or not. The documents may come from teaching and research institutions in France or abroad, or from public or private research centers.
L'archive ouverte pluridisciplinaire HAL, est destinée au dépôt et à la diffusion de documents scientifiques de niveau recherche, publiés ou non, émanant des établissements d'enseignement et de recherche français ou étrangers, des laboratoires publics ou privés. 
Tau R3-R4 Domain Dimer of the Wild Type and Phosphorylated Ser356 Sequences. I. In Solution by Atomistic Simulations

Philippe Derreumaux, ${ }^{a b^{*}}$ Viet Hoang Man, ${ }^{c}$ Junmei Wang, ${ }^{c}$ Phuong H Nguyen ${ }^{d, e}$

${ }^{a}$ Laboratory of Theoretical Chemistry, Ton Duc Thang University, Ho Chi Minh City, Vietnam

${ }^{b}$ Faculty of Pharmacy, Ton Duc Thang University, Ho Chi Minh City, Vietnam

c Department of Pharmaceutical Sciences, School of Pharmacy, University of Pittsburgh, Pittsburgh, Pennsylvania 15261, United States.

${ }^{d}$ CNRS, Université de Paris, UPR 9080, Laboratoire de Biochimie Théorique, 13 rue Pierre et Marie Curie, F-75005, Paris, France

e Institut de Biologie Physico-Chimique, Fondation Edmond de Rothschild, PSL Research University, Paris, France 
ABSTRACT: In Alzheimer's disease, neurofibrillary lesions correlate with cognitive deficits and consist of inclusions of tau protein with cross- $\beta$ structure. A stable dimeric form of soluble tau has been evidenced in the cells, but its high-resolution structure is missing in solution. We know, however, that cryo-electron microscopy (c-EM) of full-length tau in the brain of an individual with AD displays a core of eight $\beta$-sheets with a $\mathrm{C}$-shaped architecture spanning the R3-R4 repeat domain, while the rest of the protein is very flexible. To address the conformational ensemble of the dimer, we performed atomistic replica exchange molecular dynamics simulations on the tau R3-R4 domain starting from the c-EM configuration. We find that the wild type tau R3-R4 dimer explores elongated, Ushaped, V-shaped and globular forms rather than the C-shape. Phosphorylation of Ser356, pSer356, is known to block the interaction between the tau protein and the amyloid- $\beta 42$ peptide. Standard molecular dynamics simulations of this phosphorylated sequence for a total of 5 microseconds compared to its wild type counterpart show a modulation of the population of $\beta$-helices and accessible topologies, and a decrease of intermediates near the fibril like conformers. 


\section{INTRODUCTION}

The intracellular formation of tau tangles and the extracellular formation of amyloid- $\beta$ ( $A \beta$ ) senile plaques are the two hallmarks in the brain of Alzheimer's disease (AD) patients. ${ }^{1,2}$ The misfolding and aggregation of these two intrinsically disordered proteins (IDPs) pass through cellular membranes, spread across different brain regions and talk to each other. ${ }^{3-5}$ In human brain, the $A \beta$ peptides consist mainly of 40 and 42 amino acids but also of many truncated and $\mathrm{N}$ terminally modified $A \beta$ versions. ${ }^{6}$ Full-length tau (2N4R, 441 residues) consists of a charged $\mathrm{N}$-terminal region, a proline-rich region PRR followed by four repeats (labelled R1 to R4) that under physiological conditions bind to the axonal microtubule, and a C-terminal region. Tau, predominantly found in axons, is present as six isoforms ranging from 352 amino acids to its full length. Tau has as many as 84 putative phosphorylation sites targeting serine, threonine and tyrosine amino acids mainly localized in the PPR and C-terminal regions. ${ }^{7}$ Tau isolated from patients shows on average 20 modified phosphorylation sites, and the ratios of isoforms and the level of phosphorylation contribute to its normal and abnormal activity. ${ }^{7-10}$

Disease-linked modifications very often favour the occurrence of the tau domain repeat R1-R4 spanning residues $244-368$, also called $\mathrm{K} 18,{ }^{11}$ and this region recapitulates much of the aggregation property of tau441 in animal models. ${ }^{12}$ The K19 tau construct includes the three repeats R1, R3 and R4. There is experimental evidence that the two hexapeptides called PHF6* (residues 275-280 in R2) and PHF6 (residues 306-311 in R3) are essential for tau aggregation and amyloid formation. ${ }^{4,13}$ In addition, formation of fibrillar tau aggregates is enhanced in the presence of polyanions such as heparin and RNA molecules and can be seeded in the presence of preformed tau aggregates in vitro and in cells. ${ }^{14}$ 
Cryo-electron microscopy (c-EM) of the tau 2N4R protein from the brain of an individual with $A D$ has revealed the amyloid fibril core of eight $\beta$-strands adopting a C-shaped architecture spanning residues 306-378 and thus including the R3-R4 domain, and no well-defined structure elsewhere. Two types of tau fibrils with in-register parallel $\beta$-sheets were revealed with different packing and orientation of the filaments. ${ }^{15}$ In contrast, in vitro heparin-fibrillized 2N4R tau displays a different picture. The rigid core spans R2-R3 and adopts a hairpin-like conformation, R1 and R4 repeats with $\beta$-strand character are semi-rigid, PRR displays large-amplitude anisotropic motions, and the two termini are flexible. ${ }^{16}$ However, double electron-electron resonance spectroscopy showed that heparininduced tau filaments are markedly different from $A D$ filaments. ${ }^{17}$ Looking at the fibrils of tau fragments, the N-acetylated PHF6-amide peptide forms parallel $\beta$ sheets by its own. ${ }^{18}$ The fragment 306-336 spanning the R3 repeat forms cross- $\beta$ structure with parallel $\beta$-sheets and three $\beta$-strands, and is able to induce aggregation of tau's microtubule-binding region in cells. ${ }^{12}$

Tau oligomers interactions with $A \beta$ peptides have been explored by numerous experimental techniques. Soluble $A \beta$ dimers isolated from $A D$ brains induce tau hyperphospholyration. ${ }^{19}$ Guo et al. suggested that the intracellular binding of soluble $A \beta 40 / 42$ peptides to soluble nonphosphorylated $2 N 4 R$ tau protein promotes tau phosphorylation and $A \beta$ nucleation using ELISA, Western blotting and surface plasmon resonance. ${ }^{20}$ Using multiple biophysical experiments, Wallin et al. showed that the full-length tau protein of 441 amino acids blocks in vitro amyloid formation of the $A \beta 40$ peptide at the oligomeric stage and the $A B 40$ monomer remains unstructured in the presence of tau. ${ }^{21}$ Interestingly, phosphorylation of Thr212, Ser214, Ser356 and Ser396 completely blocks $A \beta 42$ binding. ${ }^{20}$ 
As NMR structures of tau monomer and oligomers are not available, computer simulations were used with various force fields and protein/solvent representations to characterize the dominant states of full-length and tau constructs. In contrast to many simulations on $A \beta$ peptides, ${ }^{2,22-29}$ a few simulations were carried out on tau. Small oligomers of PHF6 fragment, ${ }^{30,31}$ and the dimer of the fragment spanning residues 273-284 (containing PHF6* and called $\mathrm{R} 2 / \mathrm{wt}),{ }^{32}$ were investigated by atomistic MD simulations. The self-assembly of individual and binary mixtures of the tau fragments R3/wt (spanning residues 306-317 and containing PHF6) and R2/wt was characterized by replica exchange molecular dynamics simulations (REMD). ${ }^{33}$ Computational formation of PHF6 fibril was also studied by much simpler protein representations. ${ }^{34,35}$

Combining NMR spectroscopy and the conformational algorithm Flexiblemeccano, Akoury et al. remodelled the equilibrium ensemble of tau K18 monomer by an aggregation enhancer polyglutamic. ${ }^{36}$ Tau441 monomer conformation was investigated using Monte Carlo simulations, a coarse-grained (CG) model, repulsive Lennard-Jones interactions and single molecule fluorescence resonance energy transfer-derived mean inter-residue separations constraints. It was found that the mean radius of gyration $(\mathrm{Rg})$ of tau increases from 5.1 to $6.0 \pm 0.5 \mathrm{~nm}$ at $293 \mathrm{~K}$ upon addition of heparin. ${ }^{37}$ Baul et al. characterized the structural features of IDPs from 20 to 441 amino acids and were able using CG simulations to reproduce the experimental $\mathrm{Rg}$, and the full scattering intensity profiles in excellent agreement with small-angle $\mathrm{X}$-ray scattering experiments. ${ }^{38}$

Recently, Popov et al. used atomistic discrete molecular dynamics (DMD) guided by structural proteomics data resulting from short-range cross-linkers (reagents) and mass spectrometry experiments to characterize the monomeric structure of tau441 in solution. ${ }^{39}$ The most populated clusters were found to 
deviate by less than $0.3 \mathrm{~nm}$ RMSD (root mean square deviation) from the DMD structures by unbiased atomistic MD simulations of 50 ns in 3 replicates. In solution, tau consists of an ensemble of compact globular conformations with transient $\alpha$-helices and $\beta$-strands, with the $\mathrm{C}$-terminal and $\mathrm{N}$-terminal regions confined on both sides on the core. Interestingly, the R3-R4 domain contains seven out of eight beta-strands (exception being the $\beta 2$ strand) of the fibril core reported by c-EM. This result runs in contrast to atomistic REMD simulations of tau K18 and K19 monomers, using 48 replicas each of 100 ns starting from 24 different structures obtained by multiple approaches including on-line servers, albeit high $\beta$-sheet content and large hydrophobic surface exposure of the motifs PHF6* and PHF6 were identified. ${ }^{40}$

Finally, Nussinov et al. showed that filaments of $3 R$ and $4 R$ tau proteins are distinct ${ }^{41}$ and studied cross-seeding and conformational selection between $3 \mathrm{R}$ and $4 \mathrm{R}$ human tau proteins. ${ }^{42}$ They also investigated how single mutations changed the population of four-repeat tau fibrils, ${ }^{43}$ and demonstrated that the $\mathrm{C}$-shaped form is stable only for R3-R4, while R1-R2 adopts a linear shape using all-atom 100 ns MD simulations of octamers starting from the c-EM C-shaped structure. ${ }^{44}$

As the formation of tau dimers appears to be the rate-limiting step for tau aggregation in vitro, ${ }^{45}$ a stable dimeric form of soluble tau has been evidenced in the cells, ${ }^{46}$ and a lot of the tau protein detected in cerebrospinal fluid from $A D$ patients has a molecular weight similar to dimers and oligomers of truncated tau, ${ }^{47}$ knowledge of the equilibrium tau dimer ensemble is critical. Because folding tau2N4R dimer from randomly chosen states is impossible at an atomic level of description by computer simulations, ${ }^{48}$ here we resort to the $c-E M$ structure of the R3-R4 repeat for starting our REMD simulations in explicit solvent. This structure is reasonable as a starting point for the dimer, as the tau441 conformation in 
solution ${ }^{39}$ and the c-EM configuration ${ }^{15}$ display very high similarity of $\beta$-strands. Then, using the most populated REMD centroids, the impact of phosphorylation at Ser356 known to block $A \beta 42$ peptide ${ }^{20}$ is analysed by using $5 \mu$ S MD simulations at $305 \mathrm{~K}$ on both the wild type and its phosphorylated tau306-378 dimeric counterpart.

\section{METHODS}

We used the GROMACS version 2018 for MD and REMD simulations. ${ }^{49}$ The all-atom force field AA-OPLS ${ }^{50}$ was used for both sequences because AA-OPLS parameters are available for the phosphorylated serine amino acid. ${ }^{51}$ Tau306-378 is capped by acetyl and amide at $\mathrm{N}$ - and $\mathrm{C}$ - termini, and at $\mathrm{pH} 7$ has deprotonated Glu and Asp, protonated Arg and Lys, and neutral His with a protonated $\mathrm{N} \varepsilon$ atom. All the simulation parameters such as the time-step, the calculation of electrostatic interactions and van der Waals interactions with cut-off distances, as well as the algorithm to control the temperature are described in Ref. 52. The TIP3P water model was used in all cases. ${ }^{53}$

The c-EM structure of WT tau306-378 dimer, shown on Figure 1, was first centred in a very large octahedron box of dimension $10.3 \mathrm{~nm}$, i.e., with a water shell of $1.5 \mathrm{~nm}$. In total, the system consists of 27139 water molecules, 10 chloride ions, and a total number of 83719 atoms. The WT system was first minimized and equilibrated at $305 \mathrm{~K}$ by a $1 \mathrm{~ns}$ MD simulation with backbone and side-chain restraints, and explored by a first REMD simulation with 60 replicas each of $30 \mathrm{~ns}$ from 305 to $370 \mathrm{~K}$. The REMD simulation was then pursued using 40 replicas from 305 to $370 \mathrm{~K}$, each of $35 \mathrm{~ns}$, in a smaller water box (octahedron box of dimension $8 \mathrm{~nm}$ ), resulting in 38776 atoms. As 305 and $370 \mathrm{~K}$ are that the two temperatures shared by the two REMD, the starting structure of a replica at a given temperature in the second REMD was selected from the last structure of the first REMD, which 
has the closest temperature to the given temperature. Reducing the water box size reduces the CPU time significantly, $8 \mathrm{~ns}$ of the second REMD simulations requiring 1 week by using 40 nodes, and 24 cores per node.

Each of the five dominant REMD-identified free energy minima was subject to $1 \mu \mathrm{s}$ MD simulation for WT (with 10 chloride ions), and $1 \mu \mathrm{s}$ MD for pSer356 (with 8 chloride ions) in a large octahedron box of dimension $10.4 \mathrm{~nm}$, resulting on average in 84808 atoms. Overall, REMD data were recorded every 100 ps, and MD data were recorded every $10 \mathrm{ps}$. A total of $495000 \mathrm{MD}$ snapshots per system, the first 50 ns being excluded, was used to determine the physical impact of phosphorylation.

The time-averaged secondary structure composition of all systems was predicted using Stride program. ${ }^{54}$ An intermolecular and intra-molecular sidechain contact between hydrophobic residues or a side chain salt-bridge contact between two charged residues was considered formed when the smallest distance is less than $0.46 \mathrm{~nm}$. A hydrogen bond was defined when the distance between the donor and the acceptor is shorter than $0.35 \mathrm{~nm}$, and the angle of donor hydrogen - acceptor is larger than $135^{\circ}$. Rg, C $\alpha$ RMSD and surface accessible to solvent (SASA) were calculated with GROMACS tools. The trajectories were also analysed by computing free energy landscapes and distributions of specific intramolecular and intermolecular side chain - side chain contacts.

\section{RESULTS AND DISCUSSION}

The atomistic REMD simulation in explicit solvent used an average of 50 replicas for 65 ns. Though equilibrium is not reached, we can however assess conformational sampling by the average of exchange rates between consecutive replicas ( $24 \%$ for the first REMD, and $20 \%$ for the second REMD, data not shown), 
and a qualitative trend can be given on the REMD-derived conformational ensemble of the WT tau R3-R4 dimer at $305 \mathrm{~K}$.

The $\mathrm{Rg}$ of the dimer and each monomer is $2.3 \mathrm{~nm}$ in the fibril. The $\mathrm{Rg}$ distributions of the dimer, chain 1 and chain 2 at $305 \mathrm{~K}$ show a first peak at 1.75, $1.62 \mathrm{~nm}$ and $1.72 \mathrm{~nm}$ (populations of 22, 28, 25\%), a second peak at $2.5 \mathrm{~nm}$ of lower populations (10\%) followed by a tail up to $2.9 \mathrm{~nm}$ (Figure 2). The secondary structure (SS) content of the dimer at $305 \mathrm{~K}$, characterized by $\beta$-sheet: $36 \pm 4$, turn: $21 \pm 3$ and coil: $43 \pm 4 \%$, varies substantially from the SS in the fibril: $\beta$-sheet: 57.5, turn: 8 and coil: $34.3 \%$. The $\beta$-sheet, coil and turn contents along the sequence of the two chains are shown in Figure 3 . We identified $8 \beta$-sheet regions as in the fibril structure. In the fibril, the $\beta 1$ to $\beta 8$ strands or sheets encompass residues 306-311, 313-322, 327-331, 336-341, 343-347, 349-354, 356-363 and $368-378$, respectively. In the predicted structures, the $\beta 1, \beta 3, \beta 4$ and $\beta 8$ regions are maintained with a $\beta$-sheet averaged over the expected residues $>50 \%$, and it is noted that the PHF6 region averages about $75 \%$ of $\beta$-sheet (Figure $3 \mathrm{~A}$ ). The $\beta 5$ region keeps only the two residues $333-334$ out of six residues for $70 \%$, and the $\beta 2, \beta 6$ and $\beta 7$ regions are only populated $40 \%$ ( $\beta 6$ and $\beta 7$ ) and $30 \%(\beta 2)$ of the simulation. The $\beta$-sheets $\beta 4$ and $\beta 5$, and the $\beta$-sheets $\beta 5$ and $\beta 6$ are separated by turn contents $>50 \%$ (Figure 3B), whereas the remaining $\beta$-sheets are separated by coils (Figure 3 C).

Figure 4 shows the free energy landscape (FEL) at $305 \mathrm{~K}$ projected on the total number of side chain contacts and the C $\alpha$ RMSD with respect to the fibril structure. Averaged over $0.5 \mathrm{~ns}$ MD simulation at $305 \mathrm{~K}$, the dimer in its fibril state has 121 side-chain contacts. Two-dimensional Hartigan-Wong k-means algorithm ${ }^{55}$ was used to classify all REMD generated conformations into to five clusters, and their populations were calculated using the size of each cluster as 
described in Ref. 52. The five clusters of similar populations, the exception being the fifth cluster of $9 \%$, have a number of side chain contacts varying from 112 (S5) to 148 (S3) and RMSD varying from 1.17 (S4) to $1.45 \mathrm{~nm}$ (S2). Increasing the number of clusters by k-means would be more accurate, as we identify few states of low populations deviating by 0.9 and $1.7 \mathrm{~nm}$, but our second goal is to determine the impact of phosphorylation on the dominant states and, as shown below, these centroids are very dynamic.

The clusters S1, S3 and S4 have seven $\beta$-sheets, $\beta 8$ at the $\mathrm{C}$-terminus lacking, S2 displays eight $\beta$-sheets with shorter lengths compared to the fibril structure, e.g., $\beta 8$ encompassing residues $371-376$ vs. $368-378$ in the fibril state, and $S 5$ has the first five $\beta$-sheets. The positions of the $\beta$-sheets in each cluster are given in Supporting Information. All clusters have a $\beta$-sheet content of $42 \%$, the exception being S5 with $27 \%$. Their morphologies vary from the c-EM C-shape as seen by the differences in the intra- and inter-molecular contact maps between the configurations (Figure S1). The c-EM C-shape is characterized by one $\beta$-sheet spanning $\beta 1-\beta 2-\beta 8$, a loop spanning residues $323-335$ and $355-367$ terminated by a $\beta$-helix spanning residues 336-354.

Figure 4 shows that the $\mathrm{S} 1$ state is the most extended, characterized by a dynamic $\beta 1-\beta 2-\beta 8$ motif ( $\beta 8$ sheet RMSD of $0.24 \mathrm{~nm}$ with the PHF6 $\beta 1$-sheet partially formed), a conserved $\beta$-helix motif (RMSD of $0.21 \mathrm{~nm}$ ) and a much less curved loop region than in c-EM. S2 with a $V$ shape has the $\beta 1-\beta 2-\beta 8$ motif ( $\beta 1-\beta 2$ $\beta 8$ RMSD of 0.35 ) and a different loop conformation inducing a change in the orientation of the $\beta$-helix (pointing outward rather than inward). The S3 and S5 states are globular and compact with almost all of the features of the c-EM configuration altered: the $\beta$-helix motif is dynamic (RMSD of $0.30 \mathrm{~nm}$ in S3 and $0.34 \mathrm{~nm}$ in $\mathrm{S} 5$ ), the $\beta 1-\beta 2$ sheet is fluctuating (RMSD of $0.38 \mathrm{~nm}$ in $\mathrm{S} 3$, and $0.88 \mathrm{~nm}$ 
in S5) and the $\beta 8$ sheet is either well-formed in S3 (RMSD of $0.29 \mathrm{~nm}$ ) or destabilized in S5 (RMSD of $0.5 \mathrm{~nm}$ ). S3 is also characterized by a six-stranded $\beta$ sheet spanning the $\beta$-sheets $\beta 1, \beta 8$ and $\beta 6$. Finally, S4 has a U-shaped configuration with a labile $\beta 1-\beta 2-\beta 8$ sheet (RMSD of $0.54 \mathrm{~nm}$ ) and a well-defined $\beta$-helix. Overall, the PHF6 motif is well maintained in S2, S3 and S4, and the $\beta$-helix motif is very well maintained in S4, S1 and S2 (RMSD from 0.15 to $0.21 \mathrm{~nm}$ ).

Next, each of the five centroids was used as a starting conformation for $1 \mu \mathrm{s}$ MD simulation at $305 \mathrm{~K}$ on the WT and its pSer356 counterpart. Figure S2 shows the C $\alpha$ RMSD deviation as a function of time for each run. The states S3 and $\mathrm{S} 5$ remain near their starting structures (RMSD of $0.5 \mathrm{~nm}$ ), and the states $\mathrm{S} 1$, S2 and S4 reach $1.0 \mathrm{~nm}$ after $1 \mu \mathrm{s}$, independently of the sequence. The secondary structure compositions averaged over the time interval 50-1000 ns of all runs are given in SI. The $\beta$-sheet content decreases from 35.5 to $26 \%$ (run S1) and to $30.7 \%$ (run S3), but averaged over all simulations, the $\beta$-sheet content decreases slightly from 30.9 to $27.6 \%$ and the coil content increases moderately from 42.5 to $46.6 \%$ upon phosphorylation.

Differences in the conformational ensembles explored by the five WT and pSer356 1 Ms MD simulations can be pictured by the broad distributions of the intra-molecular distances between the $\mathrm{C} \beta$ atoms of V306-F378 ( $\mathrm{N}$ - and Cterminus), L325-V363 (centre of the loop region) and V339-I354 (end-to-end distance of $\beta$-helix) averaged over the time interval 50-1000 ns of all runs (Figure S3). The two distributions, proximal to the site of phosphorylation 356, with distances between 0.4 and $2.5 \mathrm{~nm}$, are more impacted than the V306-F378 distribution, with distances between 0.4 and $3.0 \mathrm{~nm}$. There is however no significant impact of phosphorylation on the three distributions. The dynamics of both systems can also be characterized by the distributions of intermolecular $\mathrm{C} \alpha$ 
distances characterizing the interface of six $\beta$-sheets (Figure 5). PSer356 reduces the population of contacts by a factor of 2-3 (e.g., 1354-1354, panel 5d), a factor of 1.5 (V306-V306, panel 5a), a factor of 5 (V339-V339, panel 5c), and augments the population of formed contacts between V363-V363 by a factor of 1.2 (panel 5e).

The $1 \mu$ s MD-generated snapshots of all runs are shown in Figure 6. Upon phosphorylation, there are substantial reorganizations in the final extended S1 state (RMSD of $1.3 \mathrm{~nm}$ between the two runs, with the pSer356 and WT S1 final states deviating by 1.8 and $1.1 \mathrm{~nm}$ from the c-EM conformation). The V-shaped S2 state remains formed in the final conformations (RMSD of $1.1 \mathrm{~nm}$ between the two runs, with the pSer356 and WT S2 final states deviating by 1.2 and $1.0 \mathrm{~nm}$ from the c-EM conformation). Upon pSer356, the U-shaped S4 state converts to a globular shape vs. a V-shape in WT, RMSD of $1.5 \mathrm{~nm}$ between the two runs, and final structures deviating by $1.2 \mathrm{~nm}$ from the c-EM configuration. Starting from the S3 and S5 globular states, pSer356 leads to smaller structural rearrangements in the final states (RMSD of $0.7 \mathrm{~nm}$ in run S3 and $0.4 \mathrm{~nm}$ in run S5, with the pSer356 and WT S3, S5 final states deviating by 1.3-1.5 $\mathrm{nm}$ from the c-EM conformation). The intra- and inter-molecular side chain - side chain probability contact maps using the last 50 ns of the ten simulations are shown in Figures S4-S6. Considering probabilities greater than 0.8 , the introduction of two negative charges at residue 356 reduces by $10 \%$ the total number of intra- and inter-peptide side chain contacts averaged over all simulations.

The pSer356-induced conformational change on the secondary structure along the sequence can be analysed into two groups: simulations $\mathrm{S} 3 / \mathrm{S} 5$, and simulations $\mathrm{S} 1 / \mathrm{S} 2 / \mathrm{S} 4$ as the final MD S3 and S5 states remain globular and therefore pSer356 stabilize these topologies, while the S1, S2 and S4 intermediates between the fibrillar and globular forms are impacted by pSer356. 
PSer356 converts a U shape to a globular state (S4 run), stabilizes the V-shape intermediate (S2 run) or further extends the elongated intermediate state (S1).

At the residue level in the $\mathrm{S} 3 / \mathrm{S} 5$ simulations, phosphorylation does not impact much the turn per residue (Figure S7b). PSer356 decreases the $\beta$-sheet signal of residues 315-319 ( $\beta 2$ strand), residues 336-337 ( $\beta 4$ strand) and residues 353-354 ( $\beta 6$ strand) from 50 to $10-30 \%$, and increases the $\beta$-sheet of residues 343345 ( $\beta 5$ strand) from 20 to 55\% (Figure S7a). This is accompanied by changes of the coil and turn contents in the same three regions (Figures S7b-S7c). We note that a few residues of the $\beta 1, \beta 3$ and $\beta 8$ sheets are formed $100 \%$ of the time.

PSer356 has different effects on the secondary structure of the S1/S2/S4 simulations. Phosphorylation decreases the $\beta$-sheet signal of residues 336-340 ( $\beta 4$ strand) from $50 \%$ to $15 \%$, and increases the $\beta$-sheet signal of the $C$-terminal of $\beta 7$ strand and of the residues $371-327$ of $\beta 8$ strand from 50 to $90 \%$ (Figure S8a). In contrast to the $\mathrm{S} 3 / \mathrm{S} 5$ results, only the $\beta 3$-sheet is formed $100 \%$ of the time and the $\beta 2$-sheet percentage is close to zero, inducing variations in the turn and coil characters of many residues (Figure S8b-c).

Taken together our results indicate that both the WT and pSer356 systems exist in many different intra-molecular conformations and display distinct heterogeneous interfaces between the two chains. The diverse populations of dimeric structures help understand the oligomer diversity observed by single molecule fluorescence studies during the heparin-induced aggregation of the repeat region of tau. ${ }^{56}$ The fact that pSer356 reduces the population of intermediates near the fibril like conformers is also consistent with recent in vitro experiments reporting that WT K18 develops seeding activity more rapidly than pSer356 K18 in the presence of heparin. ${ }^{57}$

Another important aspect of our $5 \mu \mathrm{s}$ MD simulations on each species is 
that the $\beta$-helix motif covering residues $336-354$ displays a RMSD between 0.15 and $0.4 \mathrm{~nm}$ in $30 \%$ of the WT conformational ensemble, and this population decreases to $5 \%$ in the pSer356 ensemble. Figure S9 shows a representative MD structure from the S4 simulation superposed on the c-EM configuration (RMSD of $0.15 \mathrm{~nm})$. The specific residue-residue interactions stabilizing this motif are described in Ref. 15.

This result is important as the $\beta$-helix region has been identified in the prion-forming domain of HET-s and plays a crucial role for infection. ${ }^{58}$ This motif is mediated by specific interactions and several specific residues in this $\beta$-solenoid core can modulate prion efficacy and propagation. ${ }^{59}$ This indicates that the effect of pSer356 is deleterious for the dimer in terms of $\beta$-helix stability and scaffold for prion-like properties, while pSer356 has been suggested to be beneficial in opening the structure of the monomer. ${ }^{39}$

It is to be noted that our results on the phosphorylation of Ser356 cannot be generalized to other phosphorylation positions and a specific combination of phosphorylation sites making tau more or less prone to aggregation phosphorylation sites. ${ }^{9}$ In this context, Mancera et al. found by MD simulations that the double pThr231/pSer235 phosphorylation pattern induced an increase of transient alpha-helix and polyproline II conformations in the monomer of tau225$250,{ }^{60}$ while we do not observe almost any helices in both our WT and pSer356 systems. Similarly, Xu et al. found by using a multi-scale computational procedure that hyperphosphorylation in the $\mathrm{N}$ - and C-terminal regions of tau 441 filament models increases the solvent accessibility of the repeat R1-R4 domain. ${ }^{61}$ Our simulations show that the SASA averaged over our models does not change much: $106.6 \mathrm{~nm}^{2}$ for fibril state, $102 \mathrm{~nm}^{2}$ for WT dimer and $104 \mathrm{~nm}^{2}$ for pSer356 dimer. 


\section{CONCLUSIONS}

Our atomistic REMD and MD simulations indicate that the configurations available to the dimer of WT tau R3-R4 domain spanning residues 306-378 encompass elongated, U-shaped, V-shaped and globular structures rather than the c-EM C-shaped conformation determined for amyloids fibrils of the full-length tau protein.

Comparison of the molecular ensembles shows that phosphorylation of Ser356 not only perturbs the population of the $\beta$-helix motif spanning residues 336-354, but also induces distinct heterogeneous interfaces between the two chains compared to its WT counterpart. pSer356 modulates the population of distinct architectures by increasing the number of globular shapes and is deleterious in stabilizing intermediates near the fibril like conformers. It will be interesting to determine whether (a) the recent force fields designed for folding structured and intrinsically disordered proteins, ${ }^{62}$ and (b) the N-and C-terminal flanking regions may lead to different equilibrium structures.

The interest of having structural ensemble of tau dimers is that we can now look at the mechanistic interactions between $A \beta 42$ and tau dimers at seminal steps of $A D$ pathogenesis. This future study based on coarse-grained models, ${ }^{25,63}$ which represents a significant step compared to previous MD simulations focusing on the interactions of very short ${ }^{64}$ and of the truncated $A \beta 17-42$ peptide and one specific tau fragments of both partners, ${ }^{65}$ may be useful for the rational design of inhibitors of tau and $A \beta$ toxicities. ${ }^{66-68}$

\section{ASSOCIATED CONTENT}

\section{Supporting Information}


Additional REMD simulation results: $\beta$-sheet locations in the five centroids, and intra-molecular and inter-molecular contact maps of the predicted centroids and the c-EM configuration. Additional MD simulation results of the wild-type and the phosphorylated Ser356 dimer: backbone RMSD from the REMD-predicted centroids, secondary structure compositions, distribution of three intra-molecular distances, contact maps of all final MD generated structures, secondary structure profiles along the sequence, and a representative MD structure. The material is available free of charge via the Internet at http://pubs.acs.org.

\section{AUTHOR INFORMATION}

\section{Corresponding Author}

*E-mail: philippe.derreumaux@tdtu.edu.vn.

\section{ORCID}

Junmei Wang : 0000-0002-9607-8229

Viet Hoang Man : 0000-0002-8907-6479

Phuong H. Nguyen: 0000-0003-1284-967X

Philippe Derreumaux: 0000-0001-9110-5585

\section{Notes}

The authors declare no competing financial interest.

\section{ACKNOWLEDGMENTS}

We thank the support of CINES (grants A0050710633 and A0060710174), University of Paris, and the French State (Grant "DYNAMO", ANR-11-LABX-001101, and "CACSICE", ANR-11-EQPX-0008). PD thanks the support of CNRS and Université de Paris.

\section{REFERENCES}

(1) Selkoe, D. G.; Hardy, J. The Amyloid Hypothesis of Alzheimer's Disease at 25 Years. EMBO Mol. Med. 2016, 8, 595-608. 
(2) Nasica-Labouze, J; Nguyen, P.H.; Sterpone, F.; Berthoumieu, O.; Buchete, N.V.; Coté, S.; De Simone, A.; Doig, A.J.; Faller, P.; Garcia, A. et al. Amyloid beta Protein and Alzheimer's Disease: When Computer Simulations Complement Experimental Studies. Chem Rev. 2015, 115, 3518-3563.

(3) Ittner, L.M. ; Götz, J. Amyloid- $\beta$ and Tau--A Toxic Pas de Deux in Alzheimer's Disease. Nat Rev Neurosci. 2011, 12, 65-72.

(4) Mohamed, N.V.; Herrou, T.; Plouffe, V.; Piperno, N.; Leclerc, N. Spreading of Tau Pathology in Alzheimer's Disease by Cell-to-Cell Transmission. Eur J Neurosci. 2013, 37, 1939-1948.

(5) Sanders, D.W. ; Kaufman, S.K. ; DeVos, S.L. ; Sharma, A.M. ; Mirbaha, H. ; Li, A. ; Barker S.J. ; Foley, A.C. ; Thorpe, J.R. ; Serpell, L.C. et al. Distinct Tau Prion Strains Propagate in Cells and Mice and Define Different Tauopathies. Neuron. 2014, 82, 1271-1288.

(6) Wirths, O.; Zampar, S. Emerging Roles of $\mathrm{N}$ - and C-terminally Truncated $A \beta$ Species in Alzheimer's Disease. Expert Opin Ther Targets. 2019, 12, 991-1004.

(7) Goedert, M.; Eisenberg, D.S.; Crowther, R.A. Propagation of Tau Aggregates and Neurodegeneration. Annu Rev Neurosci. 2017, 40, 189-210.

(8) Wang, Y.; Mandelkow, E. Tau in Physiology and Pathology. Nat Rev Neurosci. 2016, 17, 5-21.

(9) Fichou, Y.; Al-Hilaly, Y.K.; Devred, F.; Smet-Nocca, C.; Tsvetkov, P.O. ; Verelst, J. ; Winderickx, J.; Geukens, N. ; Vanmechelen, E. ; Perrotin, A. et al. The Elusive Tau Molecular Structures: Can We Translate the Recent Breakthroughs into New Targets for Intervention? Acta Neuropathol Commun. 2019, 7, 3147.

(10) Hefti, M.M.; Kim, S.; Bell, A.J.; Betters, R.K. ; Fiock, K.L., Lida, M.A. ; Smalley, M.E. ; Farrell, K. ; Fowkes, M.E. ; Crary, J.F. Tau Phosphorylation and Aggregation in the Developing Human Brain. J Neuropathol Exp Neurol. 2019, 78, 930-938.

(11) Spillantini, M.G. ; Goedert, M. Tau Pathology and Neurodegeneration. Lancet Neurol. 2013, 12, 609-622.

(12) Stöhr, J. ; Wu, H. ; Nick, M. ; Wu, Y. ; Bhate, M. ; Condello, C. ; Johnson, N. ; Rodgers, J.; Lemmin, T. Acharya, S. et al. A 31-residue Peptide induces Aggregation of tau's Microtubule-Binding Region in Cells. Nat Chem. 2017, 9, 874-881.

(13) von Bergen $M$, Friedhoff $P$, Biernat J, Heberle J, Mandelkow EM, Mandelkow E. Assembly of Tau Protein into Alzheimer Paired Helical Filaments Depends on a Local Sequence Motif ((306)VQIVYK(311)) Forming Beta Structure. Proc Natl Acad Sci U S A. 2000, 97, 5129-5134.

(14) Frost, B.; Jacks, R.L.; Diamond, M.I. Propagation of Tau Misfolding from the Outside to the Inside of a Cell. J Biol Chem. 2009, 284, 12845-12852. 
(15) Fitzpatrick, A.W.P.; Falcon, B.; He, S.; Murzin, A.G.; Murshudov, G.; Garringer, H.J.; Crowther, R.A.; Ghetti, B.; Goedert, M.; Scheres, S.H.W. CryoEM Structures of Tau Filaments from Alzheimer's Disease. Nature. 2017, $547,185-190$.

(16) Dregni, A.J.; Mandala, V.S. ; Wu, H. ; Elkins, M.R. ; Wang, H.K. ; Hung, I. ; DeGrado, W.F. ; Hong, M. In vitro ON4R Tau Fibrils Contain a Monomorphic $\beta$-sheet Core Enclosed by Dynamically Heterogeneous Fuzzy Coat Segments. Proc Natl Acad Sci USA. 2019, 116, 16357-16366.

(17) Fichou, Y.; Vigers, M. ; Goring, A.K. ; Eschmann, N.A. ; Han, S. Heparininduced Tau Filaments are Structurally Heterogeneous and Differ from Alzheimer's Disease Filaments. Chem Commun (Camb). 2018, 54, 4573-4576.

(18) Goux, W.J.; Kopplin, L.; Nguyen, A.D.; Leak, K.; Rutkofsky, M.; Shanmuganandam, V.D.; Sharma, D.; Inouye, H.; Kirschner, D.A. The Formation of Straight and Twisted Filaments from Short Tau Peptides. J Biol Chem. 2004, 279, 26868-26875.

(19) Jin, M.; Shepardson, N.; Yang, T.; Chen, G.; Walsh, D.; Selkoe, D.J. Soluble Amyloid beta-protein Dimers Isolated from Alzheimer Cortex directly Induce Tau Hyperphosphorylation and Neuritic Degeneration. Proc Natl Acad Sci USA. 2011, 108, 5819-5824.

(20) Guo, J.P.; Arai, T.; Miklossy, J.; McGeer, P.L. Abeta and Tau Form Soluble Complexes that may Promote Self Aggregation of both into the Insoluble Forms Observed in Alzheimer's Disease. Proc Natl Acad Sci U S A. 2006, 103, 1953-1958.

(21) Wallin, C.; Hiruma, Y.; Wärmländer, S.K.T.S.; Huvent, I.; Jarvet, J.; Abrahams, J.P.; Gräslund, A. ; Lippens, G., Luo, J. The Neuronal Tau Protein Blocks in Vitro Fibrillation of the Amyloid- $\beta(A \beta)$ Peptide at the Oligomeric Stage. J Am Chem Soc. 2018, 140, 8138-8146.

(22) Tarus, B.; Tran, T.T.; Nasica-Labouze, J.; Sterpone, F.; Nguyen, P.H.; Derreumaux $P$. Structures of the Alzheimer's Wild-Type Aß1-40 Dimer from Atomistic Simulations. J Phys Chem B. 2015, 119, 10478-10487.

(23) Cao, Y.; Jiang, X.; Han, W. Self-Assembly Pathways of $\beta$-Sheet-Rich Amyloid- $\beta$ (1-40) Dimers: Markov State Model Analysis on Millisecond HybridResolution Simulations. J Chem Theory Comput. 2017, 13, 5731-5744.

(24) Man, V. H.; Nguyen, P. H.; Derreumaux, P. High-Resolution Structures of the Amyloid- $\beta$ 1-42 Dimers from the Comparison of Four Atomistic Force Fields. J. Phys. Chem. B 2017, 121, 5977-5987. 
(25) Sterpone, F.; Melchionna, S.; Tuffery, P.; Pasquali, S.; Mousseau, N.; Cragnolini, T.; Chebaro, Y.; St-Pierre, J.; Kalimeri, M.; Barducci, A. et al. The OPEP Protein Model: From Single Molecules, Amyloid Formation, Crowding and Hydrodynamics to 31 DNA/RNA Systems. Chem. Soc. Rev. 2014, 43, 48714893.

(26) Nguyen, P.H. ; Campanera, J.M. ; Ngo, S.T. ; Loquet, A. ; Derreumaux, P. Tetrameric $A \beta 40$ and $A \beta 42 \beta$-Barrel Structures by Extensive Atomistic Simulations. I. In a Bilayer Mimicking a Neuronal Membrane. J Phys Chem B. 2019,123, 3643-3648.

(27) Jang, H.; Teran Arce, F.; Ramachandran, S.; Kagan, B. L.; Lal, R.; Nussinov, R. Disordered Amyloidogenic Peptides May Insert into the Membrane and Assemble into Common Cyclic Structural Motifs. Chem. Soc. Rev. 2014, 43, 6750-6764.

(28) Ngo, S.T.; Nguyen, P.H.; Derreumaux, P. Impact of A2T and D23N Mutations on Tetrameric A $\beta 42$ Barrel within a Dipalmitoylphosphatidylcholine Lipid Bilayer Membrane by Replica Exchange Molecular Dynamics. J. Phys. Chem. B 2020, 124, 1175-1182.

(29) Ngo, S.T.; Nguyen, P.H.; Derreumaux, P. Stability of A $\beta 11-40$ Trimers with Parallel and Antiparallel $\beta$-sheet Organizations in a Membrane-Mimicking Environment by Replica Exchange Molecular Dynamics. J. Phys. Chem. B 2020, 124, 617-626.

(30) Levine, Z.A.; Larini, L. ; LaPointe, N.E.; Feinstein, S.C. ; Shea, J.E. Regulation and Aggregation of Intrinsically Disordered Peptides. Proc Natl Acad Sci U SA. 2015, 112, 2758-2763.

(31) Matthes, D.; Gapsys, V. ; de Groot, B.L. Driving Forces and Structural Determinants of Steric Zipper Peptide Oligomer Formation Elucidated by Atomistic Simulations. J Mol Biol. 2012, 421, 390-416.

(32) Eschmann, N.A. ; Georgieva, E.R. ; Ganguly, P. ; Borbat, P.P. ; Rappaport, M.D. ; Akdogan, Y. ; Freed, J.H. ; Shea, J.E. ; Han, S. Signature of an Aggregation-prone Conformation of Tau. Sci Rep. 2017, 7, 44739.

(33) Ganguly, P.; Do, T.D.; Larini, L. ; LaPointe, N.E. ; Sercel, A.J. ; Shade, M.F. ; Feinstein, S.C. ; Bowers, M.T. ; Shea, J.E. Tau Assembly: The Dominant Role of PHF6 (VQIVYK) in Microtubule Binding Region Repeat R3. J Phys Chem B. 2015, 119, 4582-4593.

(34) Smit, F.X.; Luiken, J.A. ; Bolhuis, P.G. Primary Fibril Nucleation of Aggregation Prone Tau Fragments PHF6 and PHF6. J Phys Chem B. 2017, 121, 
3250-3261.

(35) Cheon, M.; Chang, I.; Hall, C.K. Influence of Temperature on Formation of Perfect Tau Fragment Fibrils using PRIME20/DMD Simulations. Protein Sci. 2012, 21, 1514-1527.

(36) Akoury, E. ; Mukrasch, M.D. ; Biernat, J. ; Tepper, K. ; Ozenne, V. ; Mandelkow, E. ; Blackledge, M. ; Zweckstetter, M. Remodeling of the Conformational Ensemble of the Repeat Domain of Tau by an Aggregation Enhancer. Protein Sci. 2016, 25, 1010-1020.

(37) Nath, A.; Sammalkorpi, M.; DeWitt, D.C. ; Trexler, A.J. ; Elbaum-Garfinkle, S. ; O'Hern, C.S. ; Rhoades, E. The Conformational Ensembles of $\alpha$-synuclein and tau: Combining Single-molecule FRET and Simulations. Biophys J. 2012, 103, 19401949.

(38) Baul, U.; Chakraborty, D.; Mugnai, M.L.; Straub, J.E. ; Thirumalai, D. Sequence Effects on Size, Shape, and Structural Heterogeneity in Intrinsically Disordered Proteins. J Phys Chem B. 2019, 123, 3462-3474.

(39) Popov, K.I. ; Makepeace, K.A.T. ; Petrotchenko, E.V. ; Dokholyan, N.V. ; Borchers, C.H. Insight into the Structure of the "Unstructured" Tau Protein. Structure. 2019, 27, 1710-1715.e4.

(40) Luo, Y. ; Ma, B. ; Nussinov, R. ; Wei, G. Structural Insight into Tau Protein's Paradox of Intrinsically Disordered Behavior, Self-Acetylation Activity, and Aggregation J Phys Chem Lett. 2014, 5, 3026-3031.

(41) Siddiqua, A.; Luo, Y.; Meyer, V. Swanson, M.A. ; Yu, X. ; Wei, G.; Zheng, J.; Eaton, G.R.; Ma, B.; Nussinov, R. et al. Conformational Basis for Asymmetric Seeding Barrier in Filaments of Three- and Four-Repeat Tau. J. Am. Chem. Soc. 2012, 134, 10271-10278.

(42) Yu, X.; Luo, Y.; Dinkel, P.; Zheng, J.; Wei, G.; Margittai, M.; Nussinov, R.; Ma, B. Cross-seeding and Conformational Selection between Three- and Four-Repeat Human Tau Proteins. J. Biol. Chem. 2012, 287, 14950-14959.

(43) Meyer, V.; Dinkel, P.D. ; Luo, Y.; Yu, X.; Wei, G.; Zheng, J.; Eaton, G.R.; Ma, B.; Nussinov, R., Eaton, S.S. et al. Single Mutations in Tau Modulate the Populations of Fibril Conformers through Seed Selection. Angew Chem Int Ed Engl. 2014, 53, 1590-1593.

(44) Li, X. ; Dong, X. ; Wei, G. ; Margittai, M. ; Nussinov, R. ; Ma, B. The Distinct Structural Preferences of Tau Protein Repeat Domains. Chem Commun (Camb). 2018, 54, 5700-5703. 
(45) Schweers, O. ; Mandelkow, E.M. ; Biernat, J. ; Mandelkow, E. Oxidation of Cysteine 322 in the Repeat Domain of Microtubule-associated Protein Tau Controls the in vitro Assembly of Paired Helical Filaments. Proc Natl Acad Sci U S A. 1995, 92, 8463-8467.

(46) Wegmann, S.; Nicholls, S.; Takeda, S.; Fan, Z.; Hyman, B.T. Formation, Release, and Internalization of Stable Tau Oligomers in Cells. J Neurochem. 2016, 139, 11631174.

(47) Takeda, S. ; Commins, C. ; DeVos, S.L. ; Nobuhara, C.K. ; Wegmann, S. ; Roe, A.D. ; Costantino, I. ; Fan Z. ; Nicholls, S.B. ; Sherman, A.E. et al. Seed-competent High-molecular-weight Tau Species Accumulates in the Cerebrospinal Fluid of Alzheimer's Disease Mouse Model and Human Patients. Ann Neurol. 2016, 80, 355-367.

(48) Tuffery, P. ; Derreumaux, P. Flexibility and Binding Affinity in ProteinLigand, Protein-Protein and Multi-Component Protein Interactions: Limitations of Current Computational Approaches. J R Soc Interface. 2012, 9, 20-33.

(49) Abraham, M. J.; Murtola, T.; Schulz, R.; Páll, S.; Smith, J. C.; Hess, B.; Lindahl, E. GROMACS: High Performance Molecular Simulations through Multi-Level Parallelism from Laptops to Supercomputers. SoftwareX 2015, 1-2, 19-25.

(50) Jorgensen, W. L.; Tirado-Rives, J. The OPLS [optimized potentials for liquid simulations] Potential Functions for Proteins, Energy Minimizations for Crystals of Cyclic peptides and Crambin. J. Am. Chem. Soc. 1988, 110, 1657-1666.

(51) Rapp, C. ; Klerman, H. ; Levine, E. ; McClendon, C.L. Hydrogen Bond Strengths in Phosphorylated and Sulfated Amino Acid Residues. PLoS One. 2013, 8, e57804.

(52) Nguyen, P.H. ; Tarus, B. ; Derreumaux, P. Familial Alzheimer A2V Mutation Reduces the Intrinsic Disorder and Completely Changes the Free Energy Landscape of the Aß1-28 Monomer. J Phys Chem B. 2014, 118, 501-510.

(53) Jorgensen, W.L.; Chandrasekhar, J.; Madura, J.D.; Impey, R.W.; Klein, M.L. Comparison of Simple Potential Functions for Simulating Liquid Water. J. Chem. Phys. 1983, 79, 926-935.

(54) Frishman, D.; Argos, P. Knowledge-based Protein Secondary Structure Assignment. Proteins 1995, 23, 566-579.

(55) Hartigan, J. A.; Wong, M. A. Algorithm AS 136: A K-Means Clustering Algorithm. J. R. Stat. Soc. 1979, 28, 100-108.

(56) Kjaergaard, M.; Dear, A.J.; Kundel, F.; Qamar, S.; Meisl, G.; Knowles, T.P.J.; Klenerman, D. Oligomer Diversity during the Aggregation of the Repeat Region 
of Tau. ACS Chem Neurosci. 2018, 9, 3060-3071.

(57) Haj-Yahya, M.; Gopianth, P.; Rajasekhar, K.; Mirbaha, H.; Diamond, M.I.; Lashuel, H.A. Site-Specific Hyperphosphorylation Inhibits, Rather than Promotes, Tau Fibrillization, Seeding Capacity and Its Microtubule Binding. Angew Chem Int Ed Engl. 2019, in press, doi: 10.1002/anie.201913001.

(58) Wasmer, C.; Lange, A.; Van Melckebeke, H.; Siemer, A.B.; Riek, R.; Meier, B.H. Amyloid Fibrils of the HET-s(218-289) Prion Form a Beta Solenoid with a Triangular Hydrophobic Core. Science. 2008, 319, 1523-1526.

(59) Daskalov, A.; Gantner, M.; Wälti, M.A.; Schmidlin, T.; Chi, C.N.; Wasmer, C.; Schütz, A.; Ceschin, J.; Clavé, C.; Cescau, S. et al. Contribution of Specific Residues of the $\beta$ solenoid Fold to HET-s Prion Function, Amyloid Structure and Stability. PLoS Pathog. 2014, 10, e1004158.

(60) Lyons, A.J.; Gandhi, N.S.; Mancera, R.L. Molecular Dynamics Simulation of the Phosphorylation-induced Conformational Changes of a Tau Peptide Fragment. Proteins. 2014, 82, 1907-1923.

(61) Xu, L.; Zheng, J.; Margittai, M.; Nussinov, R.; Ma, B. How Does Hyperphopsphorylation Promote Tau Aggregation and Modulate Filament Structure and Stability? ACS Chem Neurosci. 2016, 7, 565-575.

(62) Nguyen, P.H.; Campanera, J.M.; Ngo, S.T. ; Loquet, A. ; Derreumaux, P. Tetrameric $A \beta 40$ and $A \beta 42 \beta$-Barrel Structures by Extensive Atomistic Simulations. II. In Aqueous Solution. J Phys Chem B. 2019, 123, 6750-6756.

(63) Derreumaux, P. Generating Ensemble Averages for Small Proteins from Extended Conformations by Monte Carlo Simulations. Phys Rev Lett 2000, 85, 206209.

(64) Do, T.D.; Economou, N.J.; Chamas, A.; Buratto, S.K.; Shea, J.E.; Bowers, M.T. Interactions between Amyloid- $\beta$ and Tau Fragments Promote Aberrant Aggregates: Implications for Amyloid Toxicity. J Phys Chem B. 2014, 118, 1122011230.

(65) Miller, Y.; Ma, B.; Nussinov, R. Synergistic Interactions between Repeats in Tau Protein and $A \beta$ Amyloids may be Responsible for Accelerated Aggregation via Polymorphic States. Biochemistry. 2011, 50, 5172-81.

(66) Doig, A.J.; Derreumaux, P. Inhibition of Protein Aggregation and Amyloid Formation by Small Molecules. Curr Opin Struct Biol. 2015, 30, 50-56.

(67) Doig, A. J. ; Del Castillo-Frias, M.P. ; Berthoumieu, O. ; Tarus, B. ; NasicaLabouze, J.; Sterpone, F. ; Nguyen P.H. ; Hooper, N.M. ; Faller, P. ; Derreumaux, P. Why Is Research on Amyloid- $\beta$ Failing to Give New Drugs for Alzheimer's Disease? ACS Chem Neurosci. 2017, 8, 1435-1437. 
(68) Zheng, Q.; Kebede, M.T.; Kemeh, M.M.; Islam, S.; Lee, B.; Bleck, S.D.; Wurfl, L.A.; Lazo, N.D. Inhibition of the Self-Assembly of $A \beta$ and of Tau by Polyphenols: Mechanistic Studies. Molecules. 2019, 24(12). pii: E2316 


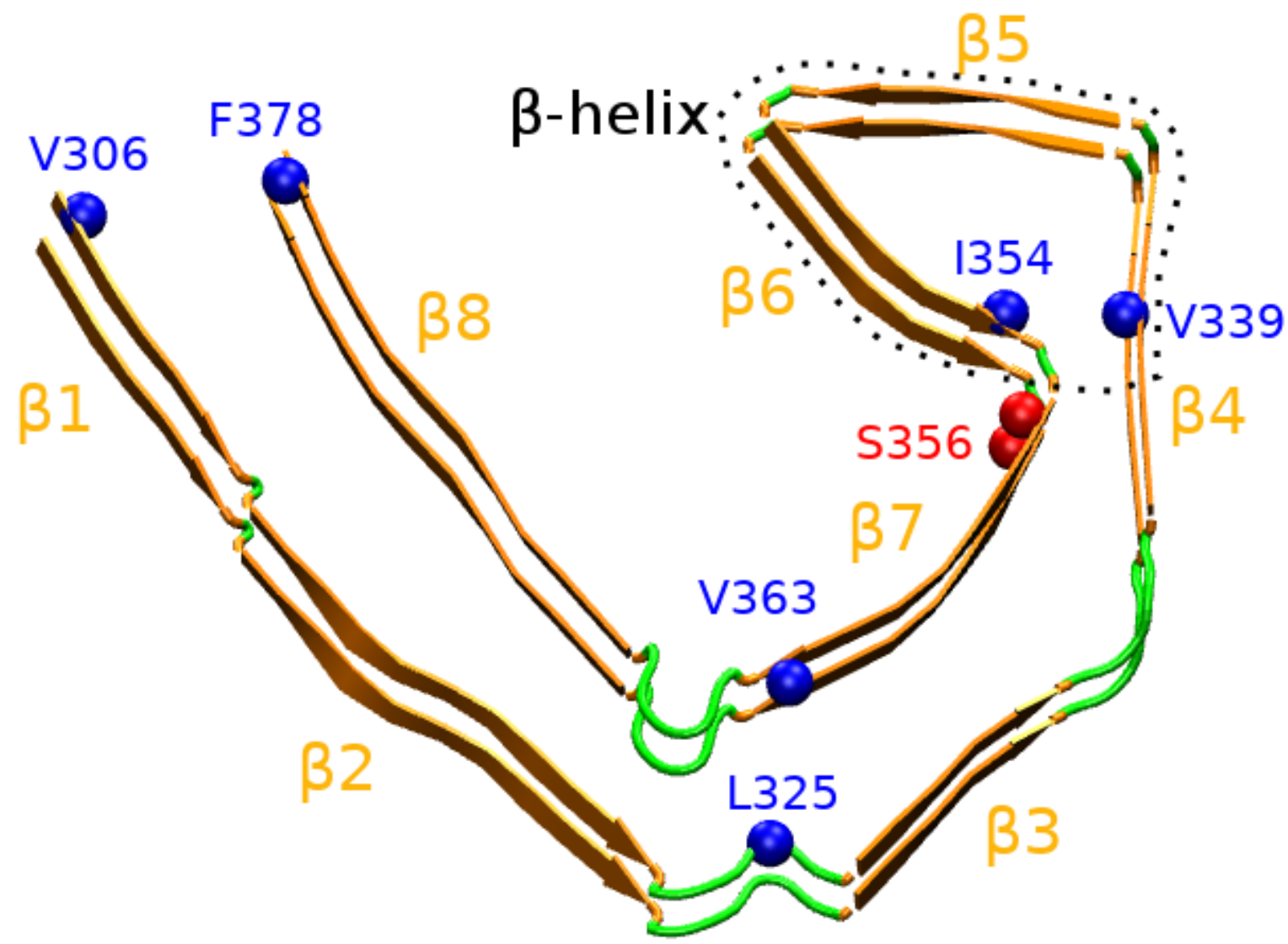

Figure 1. Structure of the cryo-EM R3-R4 tau fibril spanning the amino acids 306378 from Alzheimer's patient brain. We report important hydrophobic residues stabilizing the C-shape form (V306-F378, L325-V363 and V339-1354), the site of phosphorylation (S356), and the $8 \beta$-sheets. Intra-molecular distances between $\mathrm{C} \beta$ atoms of V306-F378, L325V363 and V339-1354 are 1.0, 0.66 and $0.57 \mathrm{~nm}$, respectively. Inter-molecular distance between C $\alpha$ atoms of V306-V306, L325L325, V339-V339, I354-I354, V363-V363 and F378-F378 is $0.49 \mathrm{~nm}$. The $\beta$-helix spans residues $336-354$, that is the $\beta 4-\beta 6$ region. 


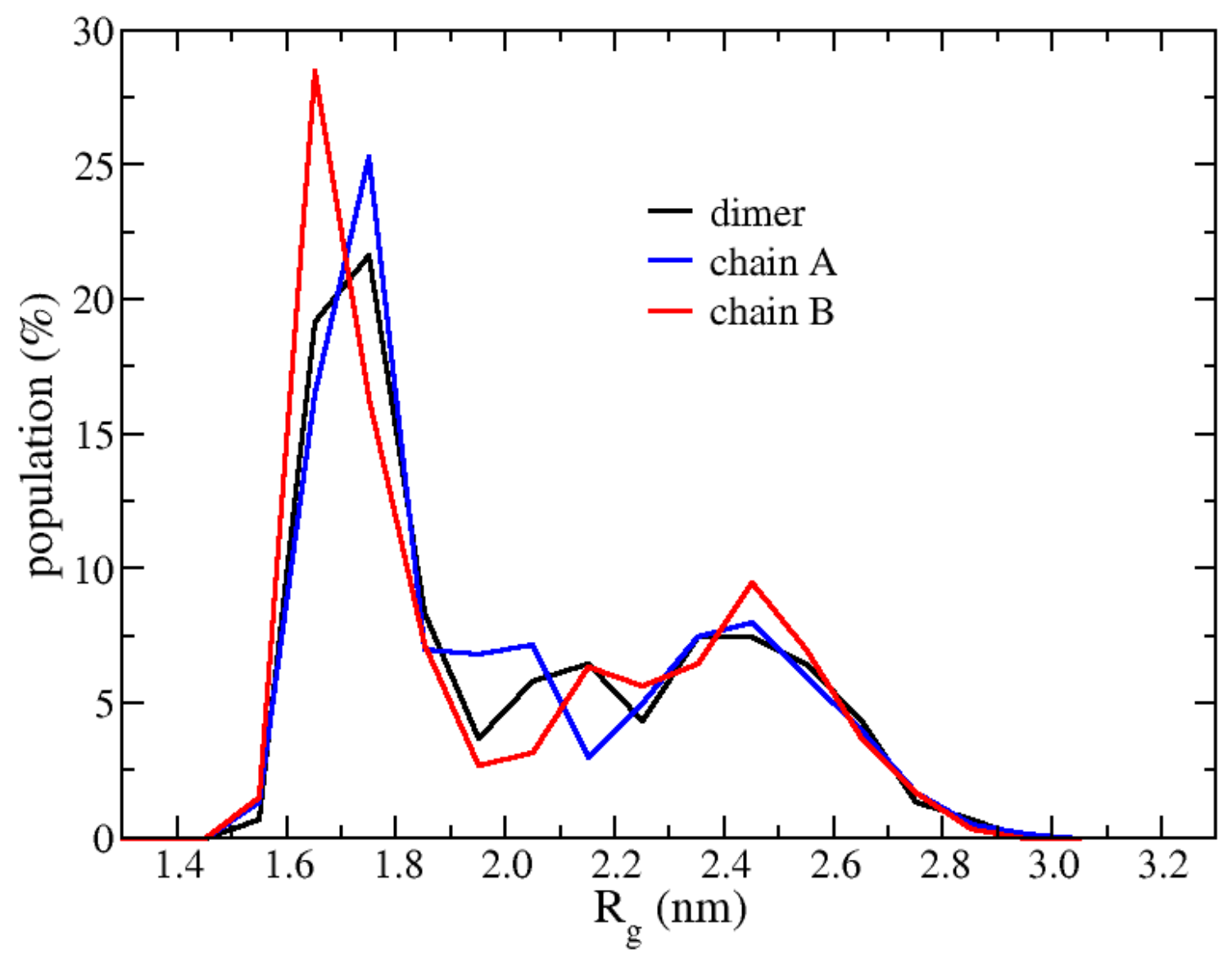

Figure 2. Distributions of the radius of gyration of each chain and the dimer of WT tau306-378 at $305 \mathrm{~K}$ using the time interval 5-65 ns from REMD simulation. 

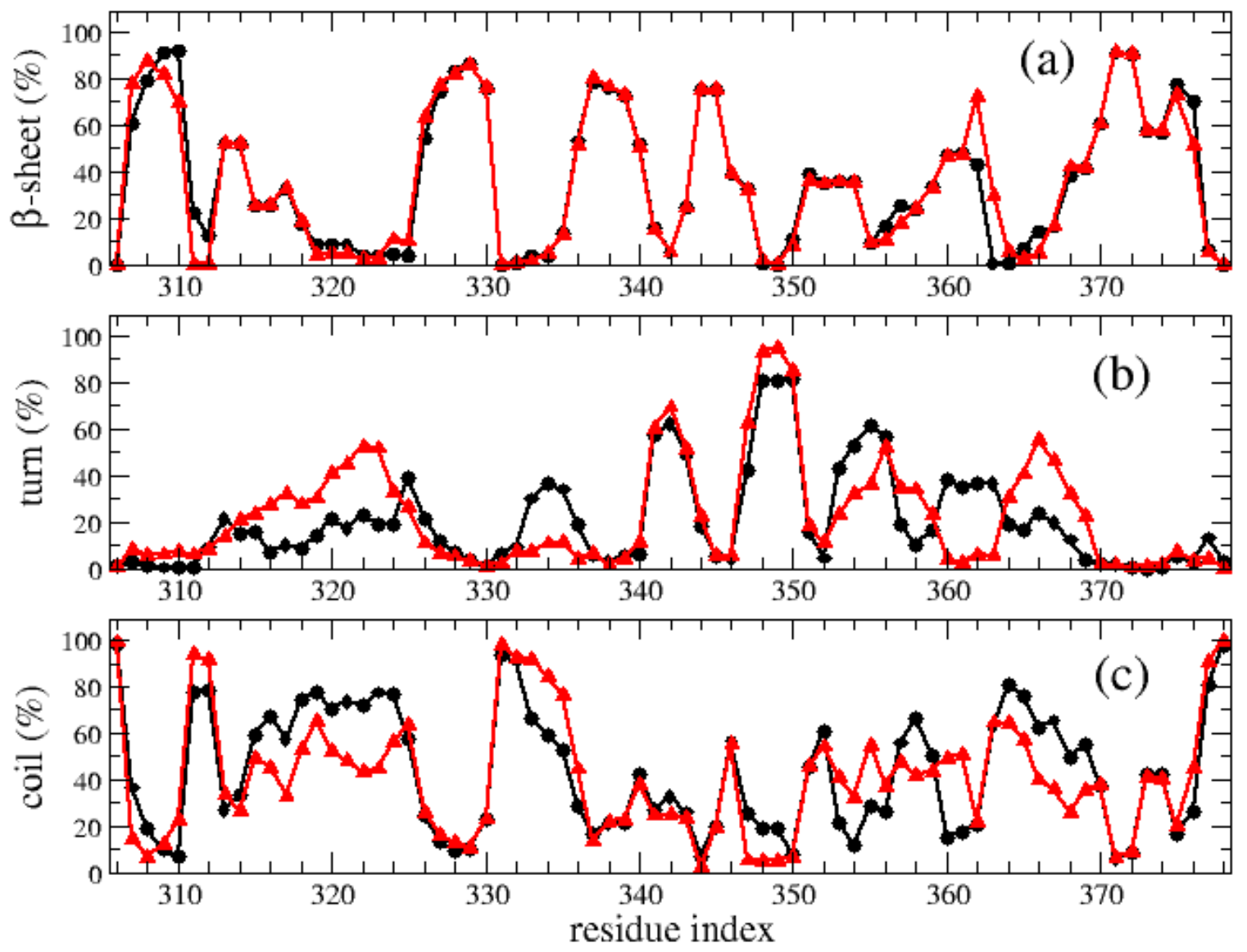

Figure 3. Secondary structure along the sequence of the WT tau306-378 dimer at $305 \mathrm{~K}$ from REMD simulations. The helix content consisting of 3-10 helix is not shown as only a signal spanning the residues $315-323$ is observed in chain B with a population of $3 \%$. Chains $A$ and $B$ are in black and red. 


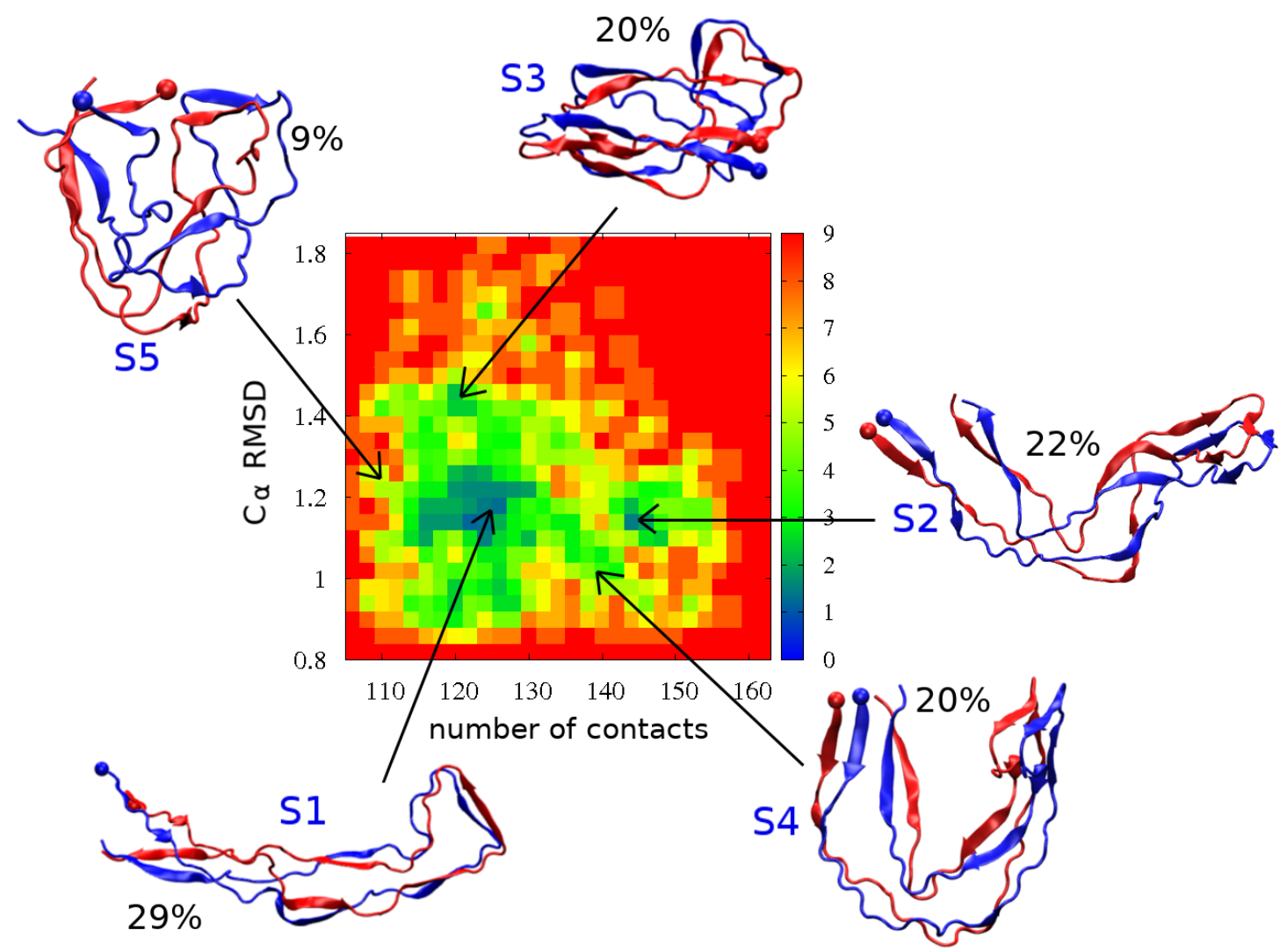

Figure 4. Free energy landscape of the WT tau306-378 dimer at $305 \mathrm{~K}$ projected on the number of inter side chain contacts and the C $\alpha$ RMSD with respective to the native fibril structure. Representative structures of the five free energy basins, S1 to S5, are shown with their populations. A ball shows the $\mathrm{N}$-terminus, chain A is in blue and chain B is in red. The colour scale is in $\mathrm{kcal} / \mathrm{mol}$. 

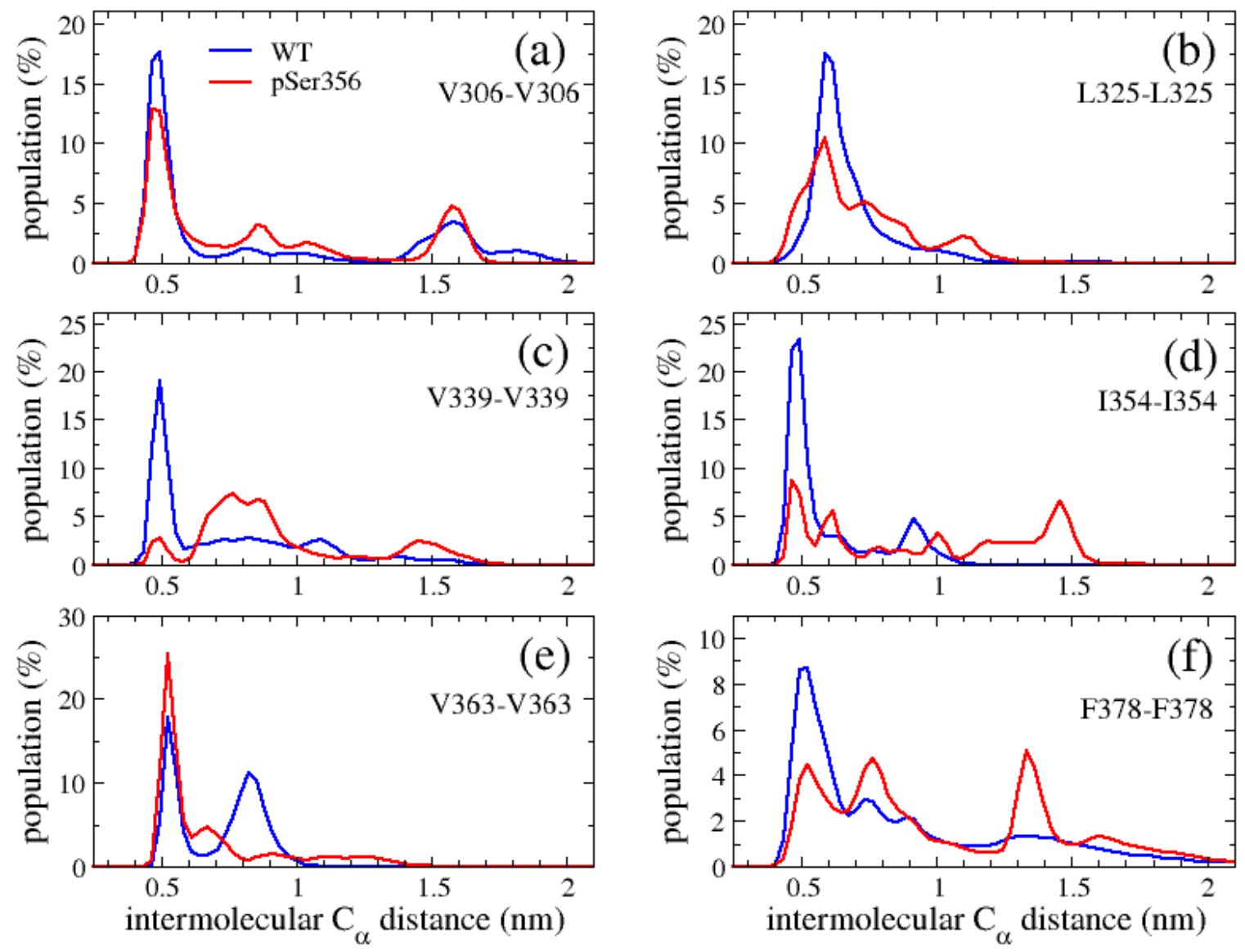

Figure 5. Distributions of intermolecular distances between the $\mathrm{C} \alpha$ atoms of two specific residues averaged over the five MD simulations of WT and pSer356. For each simulation we consider the time interval $50 \mathrm{~ns}$ to $1000 \mathrm{~ns}$ 


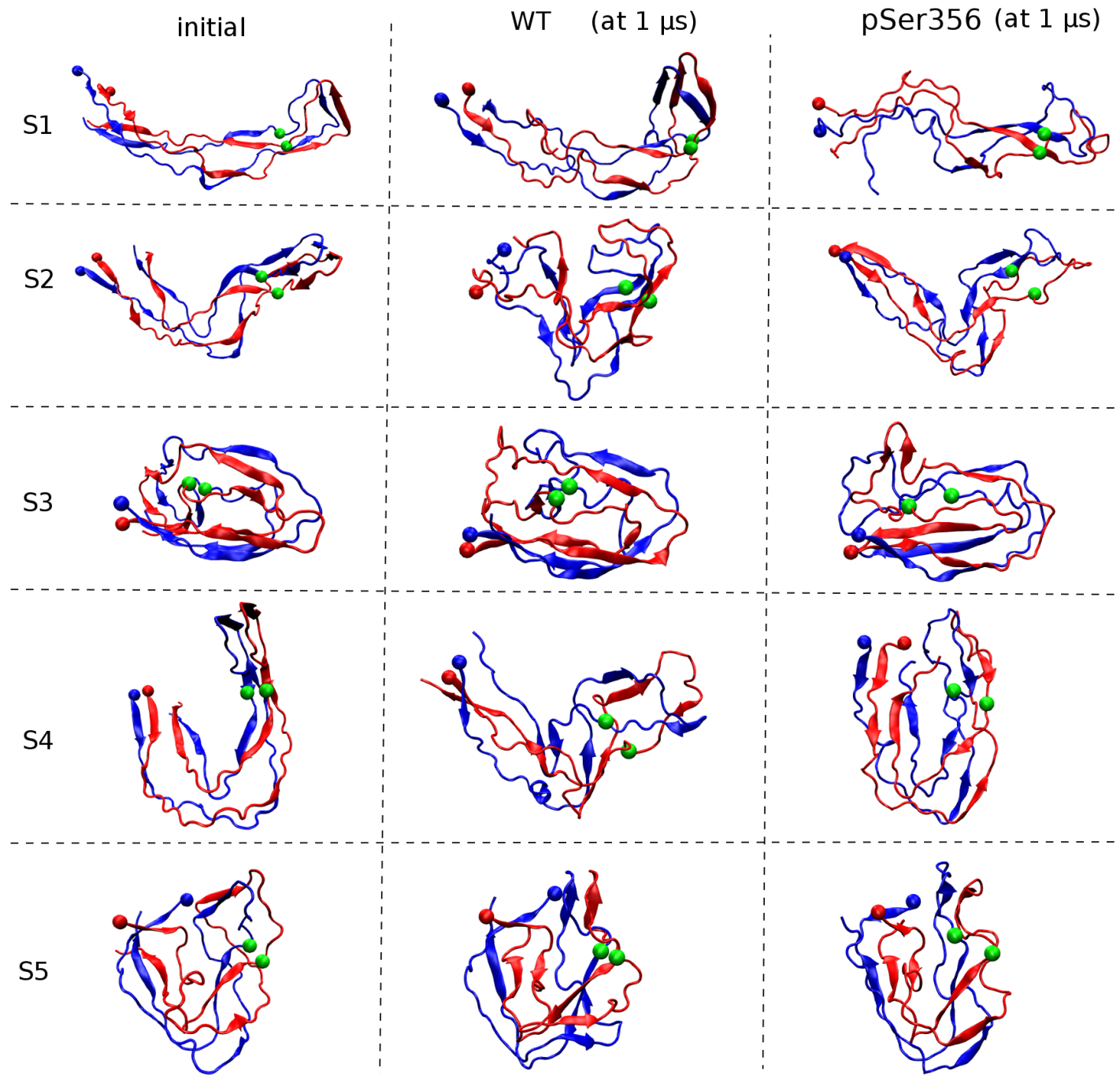

Figure 6: Initial REMD centroids (S1 to S5) and their final MD structures for the WT and pSer356 systems. The $\mathrm{N}$-terminal amino acids are visualized by red and blue balls, and the C $\alpha$ positions of the two Ser 356 and pSer356 residues by green balls. The $C \alpha$ RMSD deviation between the final WT and pSer356 structures is $1.3 \mathrm{~nm}$ (run S1), $1.1 \mathrm{~nm}$ (run S2), $0.8 \mathrm{~nm}$ (run S3), $1.5 \mathrm{~nm}$ (run S4) and $0.4 \mathrm{~nm}$ (run S5). 
30

TOC Graphics

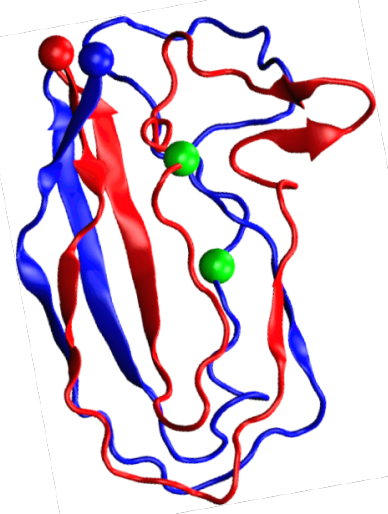

